\title{
Improved controlled atmosphere high temperature scanning probe microscope
}

Hansen, Karin Vels; Wu, Yuehua; Jacobsen, Torben; Mogensen, Mogens Bjerg; Kuhn, Luise Theil

Published in:

Review of Scientific Instruments

Link to article, DOI:

$10.1063 / 1.4811848$

Publication date:

2013

Document Version

Publisher's PDF, also known as Version of record

Link back to DTU Orbit

Citation (APA):

Hansen, K. V., Wu, Y., Jacobsen, T., Mogensen, M. B., \& Kuhn, L. T. (2013). Improved controlled atmosphere high temperature scanning probe microscope. Review of Scientific Instruments, 84(7), 073701.

https://doi.org/10.1063/1.4811848

\section{General rights}

Copyright and moral rights for the publications made accessible in the public portal are retained by the authors and/or other copyright owners and it is a condition of accessing publications that users recognise and abide by the legal requirements associated with these rights.

- Users may download and print one copy of any publication from the public portal for the purpose of private study or research.

- You may not further distribute the material or use it for any profit-making activity or commercial gain

- You may freely distribute the URL identifying the publication in the public portal 


\section{AIP}

\section{Improved controlled atmosphere high temperature scanning probe microscope}

K. V. Hansen, Y. Wu, T. Jacobsen, M. B. Mogensen, and L. Theil Kuhn

Citation: Rev. Sci. Instrum. 84, 073701 (2013); doi: 10.1063/1.4811848

View online: http://dx.doi.org/10.1063/1.4811848

View Table of Contents: http://rsi.aip.org/resource/1/RSINAK/v84/i7

Published by the AIP Publishing LLC.

\section{Additional information on Rev. Sci. Instrum.}

Journal Homepage: http://rsi.aip.org

Journal Information: http://rsi.aip.org/about/about_the_journal

Top downloads: http://rsi.aip.org/features/most_downloaded

Information for Authors: http://rsi.aip.org/authors

\section{ADVERTISEMENT}

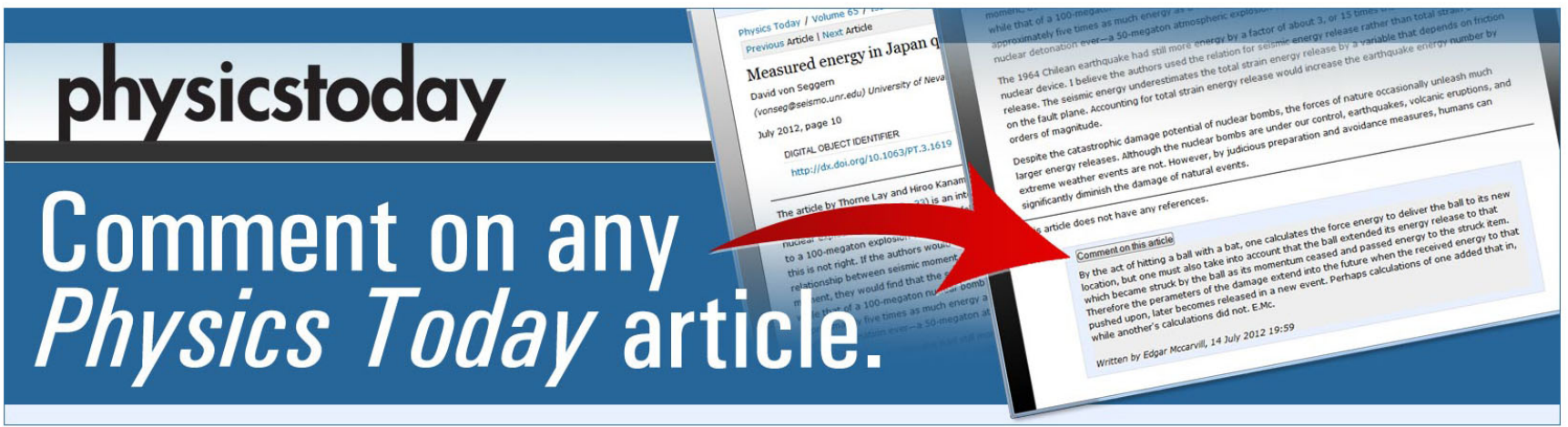




\title{
Improved controlled atmosphere high temperature scanning probe microscope
}

\author{
K. V. Hansen, ${ }^{1}$ Y. Wu, ${ }^{1}$ T. Jacobsen, ${ }^{2}$ M. B. Mogensen, ${ }^{1}$ and L. Theil Kuhn ${ }^{1}$ \\ ${ }^{1}$ Department of Energy Conversion and Storage, Technical University of Denmark, DTU Ris $\phi$ Campus, \\ Frederiksborgvej 399, DK-4000 Roskilde, Denmark \\ ${ }^{2}$ Department of Chemistry, Technical University of Denmark, Kemitorvet, DK-2800 Kgs. Lyngby, Denmark
}

(Received 11 March 2013; accepted 11 June 2013; published online 2 July 2013)

To locally access electrochemical active surfaces and interfaces in operando at the sub-micron scale at high temperatures in a reactive gas atmosphere is of great importance to understand the basic mechanisms in new functional materials, for instance, for energy technologies, such as solid oxide fuel cells and electrolyzer cells. Here, we report on advanced improvements of our original controlled atmosphere high temperature scanning probe microscope, CAHT-SPM. The new microscope can employ a broad range of the scanning probe techniques including tapping mode, scanning tunneling microscopy, scanning tunneling spectroscopy, conductive atomic force microscopy, and Kelvin probe force microscopy. The temperature of the sample can be as high as $850^{\circ} \mathrm{C}$. Both reducing and oxidizing gases such as oxygen, hydrogen, and nitrogen can be added in the sample chamber and the oxygen partial pressure $\left(\mathrm{pO}_{2}\right)$ is monitored by an oxygen sensor. We present here some examples of its capabilities demonstrated by high temperature topography with simultaneously ac electrical conductance measurements during atmosphere changes, electrochemical impedance spectroscopy at various temperatures, and measurements of the surface potential. The improved CAHT-SPM, therefore, holds a great potential for local sub-micron analysis of high-temperature and gas induced changes of a wide range of materials. (C) 2013 AIP Publishing LLC. [http://dx.doi.org/10.1063/1.4811848]

\section{INTRODUCTION}

New materials for conversion and storage of energy in a sustainable manner will be the focus of future energy technology. For instance, the performance of high temperature fuel and electrolyzer cells depends on the functionality of surfaces and interfaces. Analysis of these during operation when the processes are active is crucial to understand and design the cells. Performance characterization of solid oxide fuel cells (SOFCs) is usually carried out by electrochemical impedance spectroscopy where full cells, symmetrical cells, or model electrodes are investigated at relevant operating conditions. It is, thus, an in operando technique where the bulk electrode is characterized. In operando is defined as measurements at conditions corresponding to the operating conditions (temperature, atmosphere, and electrochemical environment), whereas in situ measurements can be defined as measurements where one or more of the parameters, temperature, atmosphere, and electrochemical environment, has the value(s) experienced under real operation.

SOFC electrodes are porous structures often consisting of more than one material phase with particle sizes in the micron and sub-micron range. The impedance spectroscopy results measured on bulk samples are an average performance of all these particles. Electrochemical and chemical reactions take place on surfaces and interfaces and a good performance is dependent on the nature of the specific locations such as the three phase boundary (TPB) and its immediate surroundings including available reaction sites. For evaluation of these locations the bulk performance is of limited use. As the cell components are continuously being improved, it becomes necessary to look more into details on how the materials are working while in operation in order to understand mechanisms on a micro- and nanometer scale. To access information on this scale the very local measurements are necessary. In the published literature there is an increasing but still a limited number of papers dealing with in situ or in operando measurements on solid oxide electrochemical cell materials. ${ }^{1-13}$

The majority of observations on development of microstructures for SOFCs are performed post mortem and after thorough preparation of the sample. As both the cool-down from operation temperature combined with the sample preparation are likely to influence the microstructure, including chemical composition, it is questionable if these type of studies give the full picture of the processes taking place during operation. However, all results are valuable and a combination of in situ and ex situ techniques is often necessary for a complete characterization.

SOFCs work at temperatures between $600^{\circ} \mathrm{C}$ and $850^{\circ} \mathrm{C}$ and require both reducing and oxidizing atmospheres. Local in situ measurements are, thus, quite demanding for the equipment, both due to stability of construction materials but also with respect to thermal drift. Local performance measurements require physical access to the part of the cell to be investigated. This often requires a model sample where preparation techniques and materials may be different from those of a real SOFC. Local impedance measurements have been performed on micro-electrodes of SOFC cathode materials by use of a microprobe station where micro-electrodes in the range $20-500 \mu \mathrm{m}$ have been contacted individually under various relevant conditions of temperature, atmosphere, and polarisation. ${ }^{14-16}$ 
The improved controlled atmosphere high temperature scanning probe microscope, CAHT2 (DME Danish Micro Engineering, Herlev, Denmark), is a novel microscope, which was developed based on experience with the prototype CAHT $1^{17-19}$ and further incorporated more scanning modes than contact mode. CAHT2 was designed for in situ electrical and electrochemical measurements and microstructural characterizations at temperatures up to $850^{\circ} \mathrm{C}$ in a controlled atmosphere. CAHT2 is able to work in oxidizing and reducing atmospheres which are not corrosive or requires special safety precautions.

As compared to CAHT1, the following extra modes are implemented in CAHT2: scanning tunneling microscopy (STM), scanning tunneling spectroscopy (STS), tapping mode, conductive AFM (C-AFM), and Kelvin probe force microscopy (KPFM).

High temperature SPMs described in the literature are typically STMs working in UHV and they can be operated at temperatures up to $850^{\circ} \mathrm{C}^{20-22} \mathrm{An}$ ambient to high pressure STM working at temperatures up to $377^{\circ} \mathrm{C}$ has been reported. References to tapping mode SPMs for use in ambient atmosphere are quite limited for temperatures above $200^{\circ} \mathrm{C}$ below which they are used for imaging organic materials, e.g., Ref. 23. One exception is an AFM described by Broekmaat et al. ${ }^{22}$ where $500{ }^{\circ} \mathrm{C}$ is mentioned as the maximum temperature for image acquisition of sample sizes of $2 \times 2 \mathrm{~mm}^{2}$ but to the best of our knowledge no images have yet been published.

\section{TECHNICAL DESCRIPTION}

As shown in Figure 1, CAHT2 is basically constructed as a normal AFM with a photo-detector, a feedback system, and a sample scanner. For the purpose of being able to obtain a controlled atmosphere around the sample and to protect the scanner and electronics the microscope is divided into three chambers: an upper chamber which contains the laser and the detector system, a sample chamber, and a lower chamber where the scanner is located. During mounting of the sam-

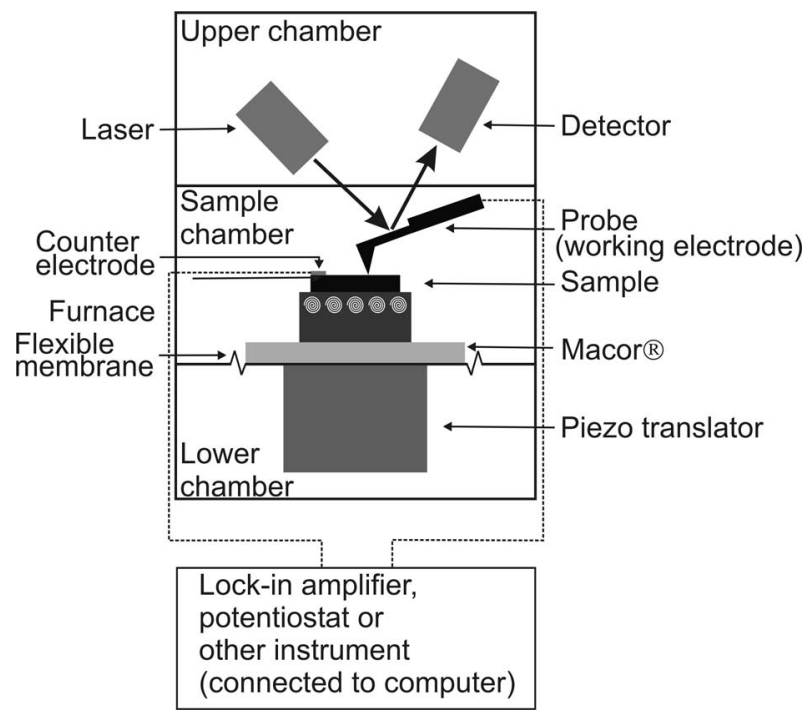

FIG. 1. Schematic drawing of the CAHT2 microscope showing the three chambers and the location of the furnace.

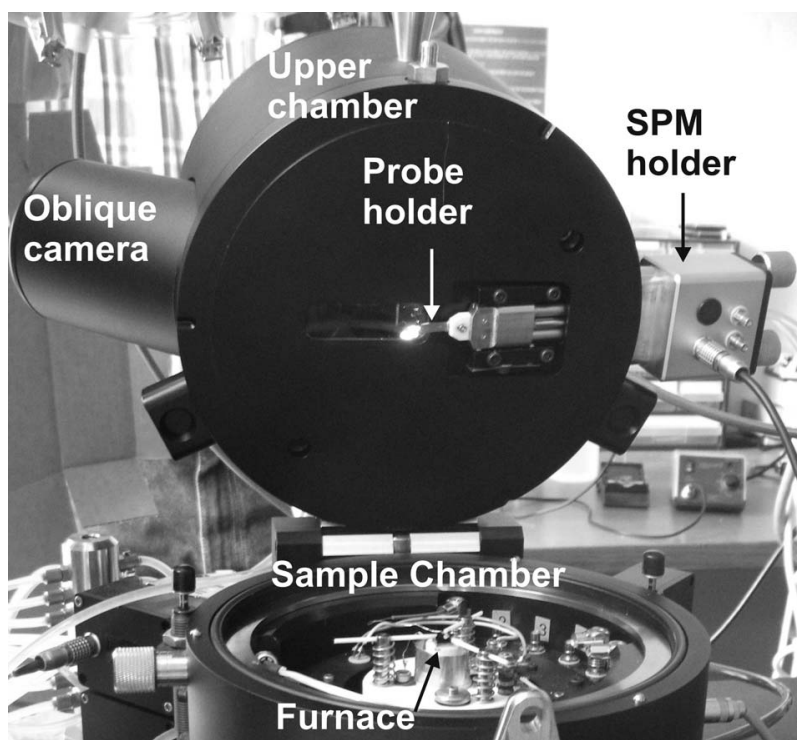

FIG. 2. The open CAHT2. The probe is located on the probe holder. The furnace with the sample on top is located in the sample chamber. When the microscope is closed, the probe is lowered to the sample.

ple on the furnace and normally during insertion of the SPM holder with the probe, the microscope is opened as seen in Figure 2. The furnace module is located on top of the scanner. The scanner thus moves the entire furnace module (Figure 3) in the $\mathrm{X}$-Y plane as well as in the Z-direction. The maximum scanning area in the $X-Y$ plane is $65 \mu \mathrm{m} \times 65 \mu \mathrm{m}$ and the range in the Z-direction is $8 \mu \mathrm{m}$. A thin flexible membrane is enabling the movement of the entire scanner-furnace while at the same time partly separating the sample chamber from the lower chamber. Cooling water in very flexible silicone tubes cools the scanner without significantly disturbing the piezomovements. Further, the furnace is mounted on a Macor ${ }^{\circledR}$ disc (Figure 3), which also serves as a thermal insulator between the furnace and the scanner.

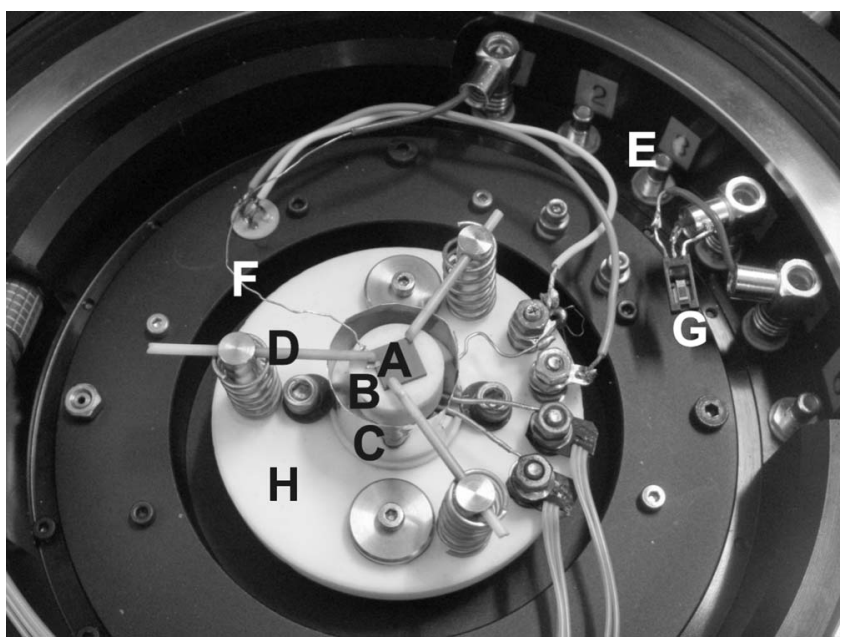

FIG. 3. The sample chamber with the furnace module mounted. A: sample, B: furnace, C: radiation shield, D: fixation pins, E: electrical connections to outside, F: electrical connection to sample, G: humidity sensor, H: Macor ${ }^{\circledR}$ disc. 
The entire bottom of the sample chamber including the sample-scanner arrangement can be moved vertically and laterally a few millimeters by screws to accommodate samples of different heights and to investigate different areas of a sample.

The furnace (Model 101275 from HeatWave Labs Inc., USA) consists of platinum and alumina. A platinum foil heat shield is surrounding it. A K-type thermocouple is placed just below the heater to control the temperature. The furnace temperature is controlled via a Eurotherm controller with a precision of $2{ }^{\circ} \mathrm{C}$. Typical sample size is in the range $5-10 \mathrm{~mm}$ in diameter. The sample is mounted on top of the furnace and is kept in place on the furnace with three spring loaded alumina pins. Platinum wires for electrical contact to the sample are also fixed with these pins. Six electrical connectors are located at the rim of the chamber. They are further connected to BNC connectors on the outside of the microscope for connection of various types of equipment such as a potentiostat.

Temperature calibration is carried out by using samples with similar geometry with an S-type thermocouple integrated into the sample surface, either with a wire connected or by using a Pt SPM-probe directly as the other half of the thermocouple. It is also possible to attach a thermocouple directly to the sample to be investigated. However, this introduces a cold leak on the sample surface and may cause interference during electrical measurements, so normally this is avoided. Also, there is a thermal gradient across the sample. The temperature at the edge, where it is possible to attach a thermocouple, is lower than in the center of the sample.

For safety reasons, the furnace temperature is limited to $1000^{\circ} \mathrm{C}$, which gives a sample temperature of $850^{\circ} \mathrm{C}$. Additional safety is employed to avoid overheating of the sensitive parts by accident. The maximum heating rate is $20^{\circ} \mathrm{C} / \mathrm{min}$. When performing experiments at elevated temperatures, it is necessary to cool the piezo-scanner, some parts of the electronics, and the SPM holder. This is achieved by flowing water in very thin and flexible plastic tubes from a central reservoir. Since these tubes are not diffusion tight for water, an accumulation of water vapor occurs in the scanner chamber. The scanner requires a humidity below $60 \%$ and, therefore, the lower chamber must be constantly purged with dry gas at a flow rate of a few liters per hour in order to keep the relative humidity low enough.

Due to the moving parts, i.e., the sample-scanner module and the bottom of the sample chamber, minor gas passage between the sample and the lower chamber is unavoidable. In order to keep a controlled atmosphere in the sample chamber there are separate gas inlets and outlets for the lower chamber and the sample chamber, respectively. Thus, a humidified gas can be lead to the sample chamber while the same dry gas can be provided to the lower chamber. Regulation of the flows can optimize the conditions in the sample chamber. The typical flow rate to the sample chamber is between 0 and $15 \mathrm{l} / \mathrm{h}$.

The flow rates of oxygen and nitrogen are controlled by mass flow controllers and can be varied over the entire $\mathrm{pO}_{2}$. The gas outlet is permanently connected to a custom-made potentiometric $\mathrm{pO}_{2}$-monitor based on zirconia ${ }^{24,25}$ to continuously measure the $\mathrm{pO}_{2}$, thus allowing for control during ex- periments in varying atmospheres such as $\mathrm{O}_{2}-\mathrm{N}_{2}$ mixtures. All gases led to the sample chamber can be humidified with $0.8 \%-8 \% \mathrm{H}_{2} \mathrm{O}$ by bubbling it through a water bottle. The reason is to have a gas with a certain water content around the sample. For some materials, e.g., solid oxide fuel cell materials, this is their natural working environment. A Pt100 thermometer measures constantly the water temperature in order to be able to determine the exact amount of humidification and the temperature of the water can at present be controlled between $10^{\circ} \mathrm{C}$ and $40^{\circ} \mathrm{C}$. When using dry $\mathrm{N}_{2}$, it is possible to reach a $\mathrm{pO}_{2}$ of $1 \times 10^{-4}$ bars. Data such as furnace, water, piezo and sample temperature, $\mathrm{pO}_{2}$, gas flows, and humidity are continuously logged in order to ensure documentation of operation conditions.

Two CCD cameras are employed to monitor the sample and the cantilever. The cameras are particularly useful when adjusting the laser spot on the cantilever and when navigating to specific locations on the sample surface, e.g., microelectrodes. One of the two cameras is perpendicular to the sample surface and the other is located at an oblique angle (Figure 2).

At room temperature, the CAHT2 can employ normal silicon-based AFM probes. At elevated temperatures PtIr probes made in-house ${ }^{17}$ are used and they can be optimized regarding sharpness and resonance frequency for various applications of CAHT2. The probes are welded to a stainless steel probe holder $(3.4 \mathrm{~mm} \times 20 \mathrm{~mm} \times 1 \mathrm{~mm})$. The probe holder is the mounted ex situ on the SPM holder (Figure 2), which also carries the electrical connections to the probe. After mounting, the probe angle is adjusted in an alignment tool simulating the laser/detector positions in the microscope ensuring that the reflection is correct when the probe is inserted into the microscope. The SPM holder is inserted through a port in the upper part of the microscope (Figure 2). During operation, exchanging the probes can be done without opening the microscope. The probe position can be reproduced within a few microns after changing probes. This will naturally affect the atmosphere in the sample chamber unless it is air.

The SPM holders come with different functionalities, i.e., preamplifier for STM, with or without shaker for tapping mode measurements and with a thin capillary tube for sniffing gas, i.e., reaction products, near the sample surface.

An oscilloscope is permanently attached to the setup. The microscope is controlled by DME's ScanTool software.

\section{OPERATIONAL MODES}

CAHT2 has been tested in the following modes:

1. Contact mode topography with or without simultaneous electrical ac conductance measurements;

2. Impedance mode;

3. Tapping mode topography;

4. STM and STS;

5. KPFM.

\section{A. Contact mode topography and conductance}

Similar to CAHT1, ${ }^{19}$ CAHT2 can acquire conductance images. While scanning in contact mode to ensure a good 

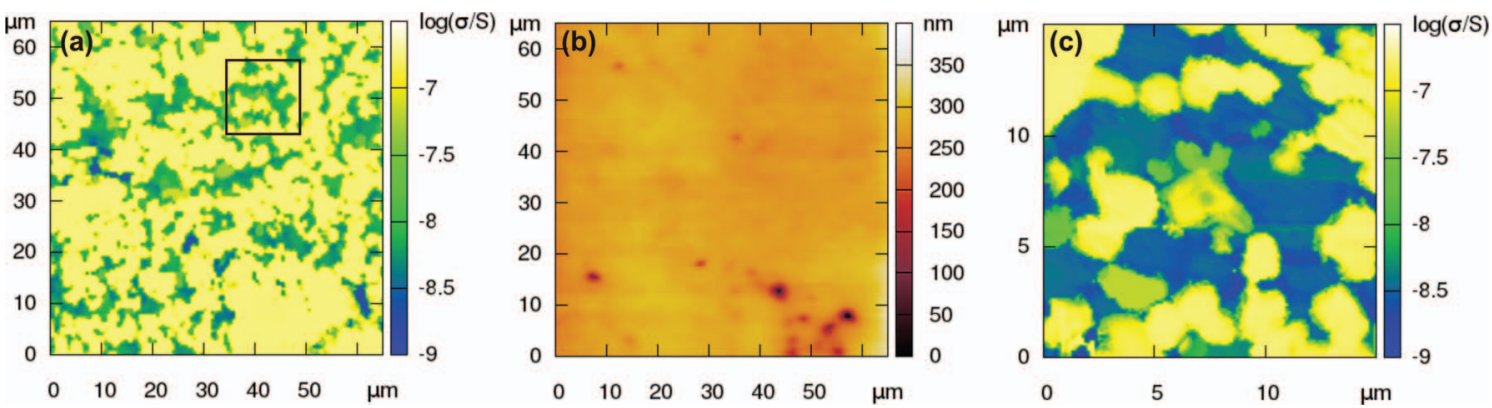

FIG. 4. Surface images of a polished LSM-YSZ sample measured at $750^{\circ} \mathrm{C}$, (a) conductance image, (b) topography image, (c) conductance image of the area marked in (a) with a higher magnification. In the conductance images, blue and yellow areas correspond to YSZ and LSM, respectively.

electrical contact, an ac electrical signal is applied through the probe and the resulting current is picked up from the sample by a Stanford SR830 lock-in amplifier. Figure 4 shows conductance and topography images of the surface of a polished lanthanum strontium manganite (LSM)/yttria-stabilized zirconia (YSZ) sample measured at $750^{\circ} \mathrm{C}$. LSM is an electronically conducting ceramic SOFC cathode material. ${ }^{26}$ As shown in Figures 4(a) and 4(c), the LSM grains (yellow) are much more conductive than the YSZ grains (blue).

Another example of the versatility is the in situ surface reduction of a NiO-YSZ composite by hydrogen. Ni-YSZ cermets are used for anode materials in SOFCs, and the reduction procedure is very determining for the performance of the anode. ${ }^{27-30}$ Figure 5(a) shows the conductance image of the unreduced $\mathrm{NiO}$. At these conditions the conductivity of $\mathrm{NiO}$ is higher than that of the YSZ and it is, thus, possible to distinguish the NiO grains (yellow and green colors). While scanning the same area, hydrogen is introduced $4 \mu \mathrm{m}$ into the image (Figure 5(b)). After this, changes occur to the sample surface, i.e., the reduction process is initiated. Firstly, the hydrogen causes an initial decrease in the surface conductance. Secondly, an increase in conductance occurs due to formation of metallic Ni. ${ }^{31}$ Due to the low temperature, the reduction does not finish during the time it takes to acquire one image (around $9 \mathrm{~min}$ ). The y-axis is thus also a time axis. The time between hydrogen introduction and $\mathrm{Ni}$ formation is identical to the incubation period described in the literature. ${ }^{32,33}$ The reason for this incubation was found by our CAHT-SPM study to be initiated by the reduction of $\mathrm{Ni}^{3+}$ to achieve a $\mathrm{Ni}^{3+} / \mathrm{Ni}^{2+}$ ratio corresponding to the potential of $\mathrm{Ni}-\mathrm{NiO} .{ }^{31}$

\section{B. Impedance mode}

This mode allows performing electrochemical impedance spectroscopy ${ }^{34}$ in selected points by using a conductive probe as the working electrode (Figure 6). It may become necessary to apply a rather large force to obtain a sufficiently good contact. For this application, the tip does not have to be sharp since the force needed to obtain electrical contact is so large that the tip will deform during measurements. A Gamry femtostat potentiostat is connected to the probe and the sample, and impedance spectra can routinely be acquired. During the impedance measurement, a sine wave is applied to the sample through the conductive probe and the electrochemical impedance response is then measured. Figure 7(a) shows impedance spectra of differently sized LSM microelectrodes on a YSZ pellet measured at $850{ }^{\circ} \mathrm{C}$ in pure oxygen. Based on the measured impedance spectra, the polarization resistance of the LSM microelectrodes was derived from equivalent circuit fitting of the measured impedance spectra. Figure 7(b) presents a double-logarithmic plot of the electrode polarization resistance versus the microelectrode diameter. A
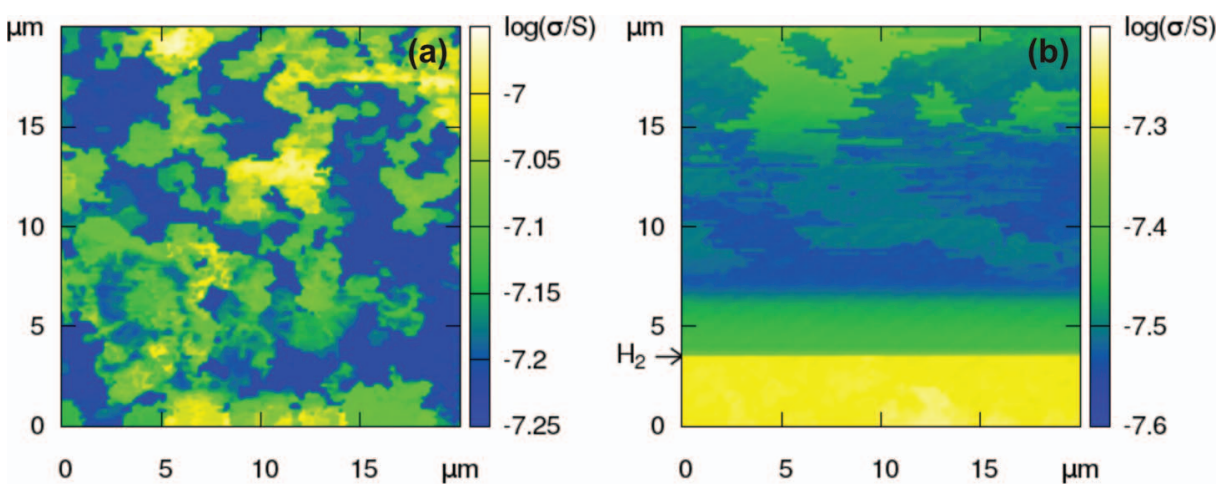

FIG. 5. Conductance of (a) NiO-YSZ surface in $\mathrm{N}_{2}$ before reduction. The conductance of YSZ is low (blue) compared to NiO (green-yellow). (b) In situ initial surface reduction of the NiO-YSZ composite. The acquisition of the image takes around 9 min and the y-axis is thus also a time axis. The arrow indicates the introduction of hydrogen. Subsequently, the conductance decreases (green to blue) and finally when Ni formation starts the conductance increases (green islands). 


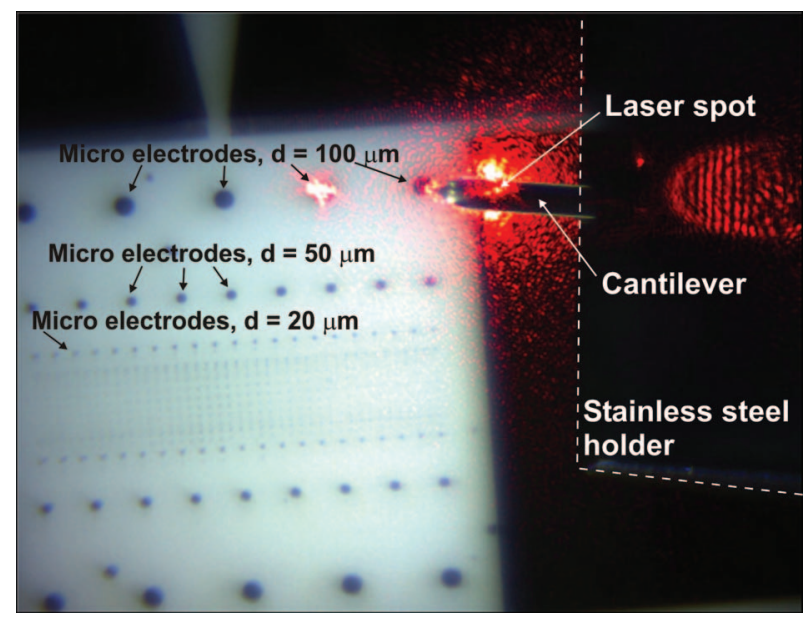

FIG. 6. Image of the sample with a probe located on a microelectrode with a diameter of $100 \mu \mathrm{m}$. The red areas are reflexes from the laser beam.

slope of 0.94 was obtained from linear regression, indicating that the polarization resistance of the LSM microelectrodes scales with the inverse of the microelectrode diameter at $850{ }^{\circ} \mathrm{C}$ in pure oxygen. ${ }^{35}$

\section{Tapping mode}

Tapping mode is much less damaging for the probe (and for the sample as well) than contact mode and, therefore, enables a larger number of images to be acquired without probe degradation. The PtIr probes for high temperature tapping mode measurements must have a suitable resonance frequency, typically around $20 \mathrm{kHz}$. Figure 8 presents tapping mode and contact mode topography images of a thermally etched YSZ surface measured at room temperature and $850^{\circ} \mathrm{C}$. The previously polished YSZ surface shows the developed grain boundary grooves, which are clearly visible at both temperatures. In addition, $1 \mathrm{~h}$ continuous scanning at $850{ }^{\circ} \mathrm{C}$ in tapping mode seems not to affect the quality of the image. In comparison, the resolution of contact mode topography is much worse because of the degradation of the probe at high temperature. This demonstrates the advantage of ac
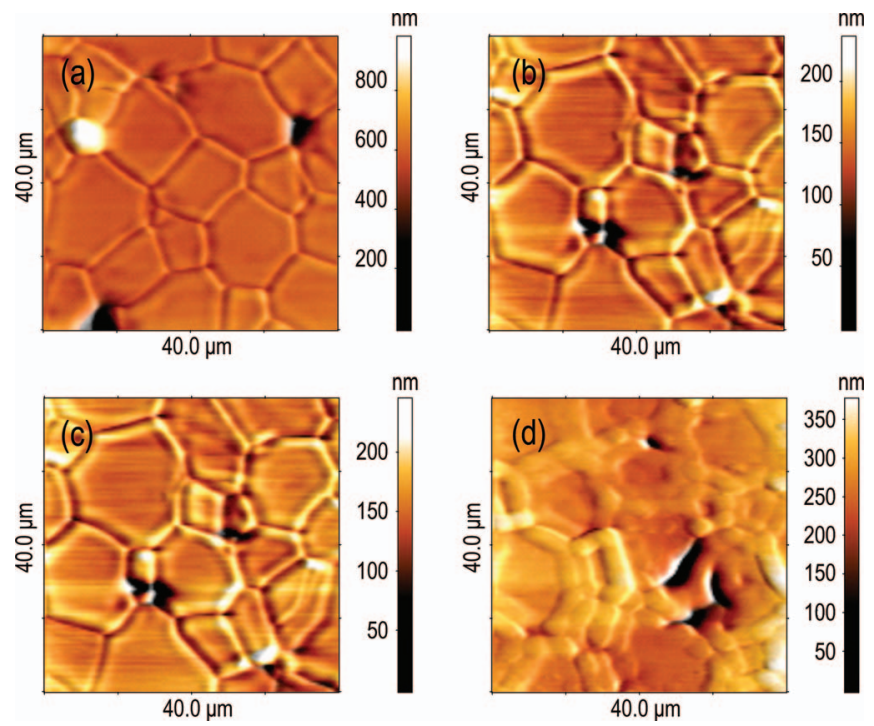

FIG. 8. Topography images on the polished surface of a sintered YSZ pellet. Tapping mode at (a) room temperature, (b) $850^{\circ} \mathrm{C}$, (c) $850^{\circ} \mathrm{C}$ after $1 \mathrm{~h}$ of scanning. (d) shows for comparison contact mode at $850^{\circ} \mathrm{C}$.

mode to depict much more clearly topographic details at high temperature for long periods of time and the improvement from CAHT1. The tapping mode allows for studying surface processes and topography changes and will be especially useful for reduction or oxidation studies.

\section{STM mode with STS}

One of the SPM holders has a build-in current preamplifier, making it possible to use a conductive probe for STM probing in constant current mode with the tunnel current flowing between tip and surface of a conductive sample. In addition to scanning across the sample, STS can be conducted at a given location by sweeping voltage and measuring current. STS gives information on the electron density of states as a function of energy. Figure 9 shows STS spectra measured on polished $\mathrm{LSM}$ at $25^{\circ} \mathrm{C}$ and at $600{ }^{\circ} \mathrm{C}$ in air. The general shape of the spectra resembles data reported in the literature, also acquired at elevated temperatures but at much
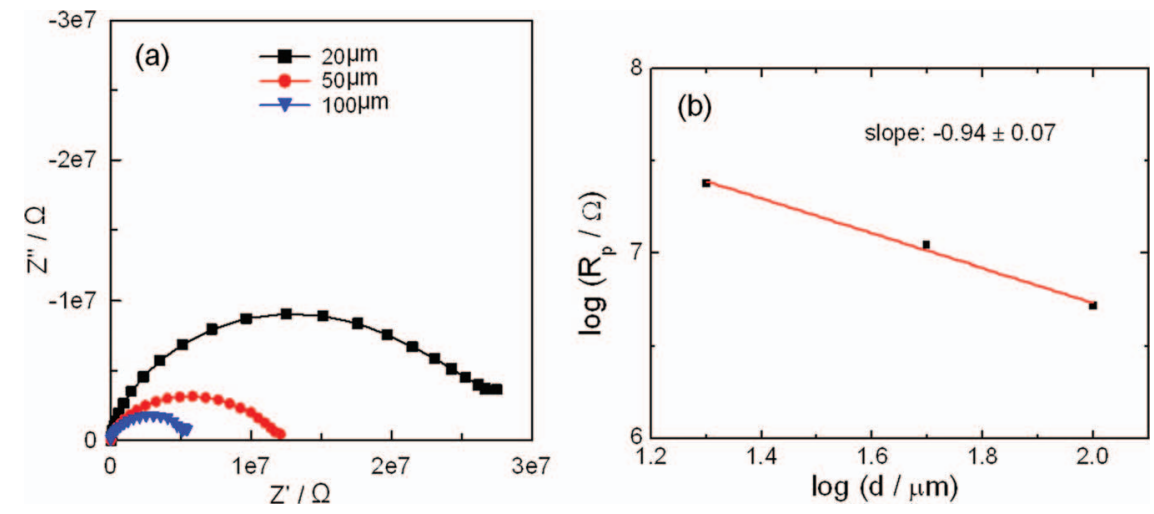

FIG. 7. (a) Impedance spectra of differently sized LSM microelectrodes on a YSZ substrate measured at $850{ }^{\circ} \mathrm{C}$ in pure oxygen. (b) Double-logarithmic plot of the LSM electrode polarization resistance, $\mathrm{R}_{\mathrm{p}}$, versus the microelectrode diameter $d$. 

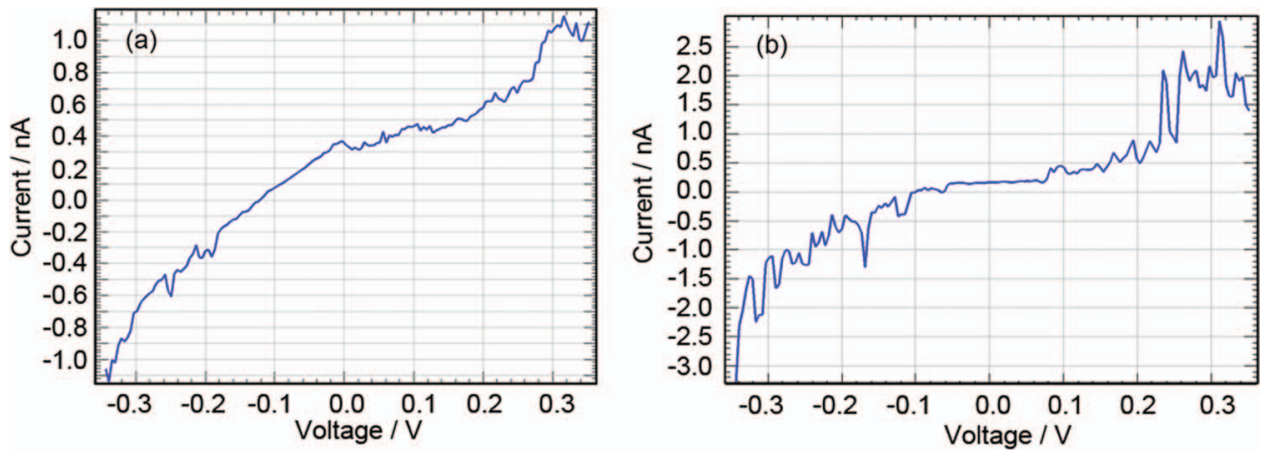

FIG. 9. Scanning tunneling spectroscopy on $\operatorname{LSM}$ (a) at $25^{\circ} \mathrm{C}$ and (b) at $600^{\circ} \mathrm{C}$ in air.

lower $\mathrm{pO}_{2}{ }^{36}$ confirming the operation capability of the STS mode at high temperature and in an active atmosphere.

\section{E. Kelvin probe force mode}

CAHT2 is able to run in a two-pass Kelvin probe force mode, where topography is picked up in contact mode or tapping mode during the first pass, and the Kelvin probe signal is acquired during the second pass at a distance from the surface. The system includes a DME Diprowa (digital programmable waveform analyzer). The combination of a lockin amplifier with a frequency generator and a feedback loop makes the instrument an ideal choice for performing Kelvin probe force measurements with an AFM, where the feedback loop can be used for regulating the bias voltage between a tip and a sample. The resonance frequency of the PtIr probes can be $10-25 \mathrm{kHz}$. KPFM is depicting the work function or surface potential of electronically conducting materials. Figure 10 shows surface potential scans (raw data) of lanthanum strontium cobaltite (LSC) electrodes on YSZ. LSC is an electronically conducting ceramic material and YSZ is an electron insulator but an ion conductor at elevated temperatures. The measurement was performed at $500^{\circ} \mathrm{C}$. The interpretation of the work function of insulating materials is not straightforward, but the demonstration shows that stable images can be obtained and that there is a clear contrast between the two materials. Further detailed analysis of such high temperature KPFM data on ion and/or electron conducting materials still remains.
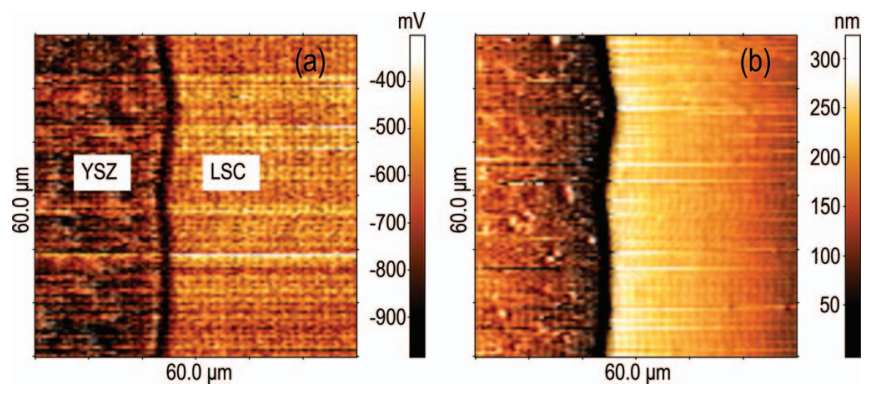

FIG. 10. YSZ and LSC measured at $500{ }^{\circ}$ C. (a) Surface potential (raw data) and (b) topography.

\section{CONCLUSION}

For demonstration some of the available CAHT2 techniques have been used for relevant SOFC studies such as the investigation of electrochemical properties of cathode microelectrodes and the process of surface reduction of an anodelike material. Further, other high temperature techniques have been demonstrated. The potential of these types of measurements to elucidate surface processes and study mechanisms is great as it can access locations at a scale not available with any other method and perform various measurements at in operando conditions.

CAHT2 is a unique and versatile instrument that can perform in situ and in operando studies of surface phenomena induced by high temperatures (up to $\sim 850^{\circ} \mathrm{C}$ ) and a reactive gas atmosphere by locally probing the topographical, electri$\mathrm{cal}$, and electrochemical properties. Both local measurements in selected points and the lateral variation of parameters can be explored with a submicron resolution despite thermal noise and drift as it can show details in conductance images down to submicron level at the present development stage.

\section{ACKNOWLEDGMENTS}

This work was supported financially by The Programme Commission on Sustainable Energy and Environment, The Danish Council for Strategic Research, via the Strategic Electrochemistry Research Center (SERC) (www.serc.dk), Contract No. 2104-06-0011, and by The Catalysis for Sustainable Energy (CASE) initiative funded by the Danish Ministry of Science, Technology, and Innovation.

${ }^{1}$ J. S. Hardy, J. W. Templeton, D. J. Edwards, Z. Lu, and J. W. Stevenson, J. Power Sources 198, 76 (2012).

${ }^{2}$ B. C. Eigenbrodt and R. A. Walker, Anal. Methods 3, 1478 (2011).

${ }^{3}$ M. Liu, M. E. Lynch, K. Blinn, F. M. Alamgir, and Y. Choi, Mater. Today 14, 534 (2011).

${ }^{4}$ F. El Gabaly, M. Grass, A. H. McDaniel, R. L. Farrow, M. A. Linne, Z. Hussein, H. Bluhm, Z. Liu, and K. F. McCarty, Phys. Chem. Chem. Phys. 12, 12138 (2010).

${ }^{5}$ A.-K. Huber, M. Falk, M. Rohnke, B. Luerssen, L. Gregoratti, and J. Janek, Phys. Chem. Chem. Phys. 14, 751 (2012).

${ }^{6}$ M. Backhaus-Ricoult, K. Adib, T. StClair, B. Luerssen, L. Gregoratti, and A. Barinov, Solid State Ionics 179, 891 (2008).

${ }^{7}$ M. Backhaus-Ricoult, K. Adib, K. Work, M. Badding, T. Ketcham, M. Amati, and L. Gregoratti, Solid State Ionics 225, 716 (2012). 
${ }^{8}$ M. B. Pomfret, J. C. Owrutsky, and R. A. Walker, Annu. Rev. Anal. Chem. 3, 151 (2010).

${ }^{9}$ A. Hagen, H. F. Poulsen, T. Klemensø, R. V. Martins, V. Honkimäki, T. Buslaps, and R. Feidenshans'l, Fuel Cells 6, 361 (2006).

${ }^{10}$ K.-C. Chang, B. Yildiz, D. Myers, J. D. Carter, and H. You, ECS Trans. 16, 23 (2009).

${ }^{11}$ P. R. Shearing, R. S. Bradley, J. Gelb, S. N. Lee, A. Atkinson, P. J. Withers, and N. P. Brandon, Electrochem. Solid-State Lett. 14, B117 (2011).

${ }^{12}$ A. Faes, Q. Jeangros, J. B. Wagner, T. W. Hansen, J. Van Herle, A. Brisse, R. Dunin-Borkowski, and A. Hessler-Wyser, ECS Trans. 25, 1985 (2009).

${ }^{13}$ T. Klemens $\varnothing$, C. C. Appel, and M. Mogensen, Electrochem. Solid-State Lett. 9, A403 (2006).

${ }^{14}$ F. S. Baumann, J. Fleig, H.-U. Habermeier, and J. Maier, Solid State Ionics 177, 1071 (2006).

${ }^{15}$ V. Brichzin, J. Fleig, H.-U. Habermeier, G. Cristiani, and J. Maier, Solid State Ionics 152-153, 499 (2002).

${ }^{16}$ G. J. la O', B. Yildiz, S. McEuen, and Y. Shao-Horn, J. Electrochem. Soc. 154, B427 (2007).

${ }^{17} \mathrm{Y}$. Wu, K. V. Hansen, T. Jacobsen, and M. Mogensen, Solid State Ionics 197, 32 (2011).

${ }^{18}$ K. Vels Hansen, C. Sander, S. Koch, and M. Mogensen, J. Phys.: Conf. Ser. 61, 389 (2007).

${ }^{19}$ K. Vels Hansen, T. Jacobsen, A.-M. Nørgaard, N. Ohmer, and M. Mogensen, Electrochem. Solid-State Lett. 12, B144 (2009).

${ }^{20}$ M. S. Hoogeman, D. Glastra van Loon, R. M. W. Loos, H. G. Ficke, E. de Haas, J. J. van der Linden, H. Zeilemaker, L. Kuipers, M. F. Chang, M. A. J. Klik, and J. W. M. Frenken, Rev. Sci. Instrum. 69, 2072 (1998).

${ }^{21}$ H. Shinagawa, T. Takamasu, and G. Kido, Physica B 298, 580 (2001).
${ }^{22}$ J. Broekmaat, A. Brinkman, D. H. A. Blank, and G. Rinders, Appl. Phys. Lett. 92, 043102 (2008).

${ }^{23}$ D. Glick, P. Thiansathaporn, and R. Superfine, Appl. Phys. Lett. 71, 3513 (1997).

${ }^{24}$ W. C. Maskell and B. C. H. Steele, J. Appl. Electrochem. 16, 475 (1986).

${ }^{25}$ A. Lund, T. Jacobsen, K. Vels Hansen, and M. Mogensen, Sens. Actuators, B 160, 1159 (2011).

${ }^{26}$ S. B. Adler, Chem. Rev. 104, 4791 (2004)

${ }^{27}$ V. A. C. Haanappel, A. Mai, and J. Mertens, Solid State Ionics 177, 2033 (2006).

${ }^{28}$ Y. Wang, M. E. Walter, K. Sabolsky, and M. M. Seabaugh, Solid State Ionics 177, 1517 (2006).

${ }^{29}$ T. S. Li, W. G. Wang, H. Miao, T. Chen, and C. Xu, J. Alloys Compd. 495, 138 (2010).

${ }^{30}$ S. L. Ebbehøj, T. Ramos, and M. Mogensen, ECS Trans. 45, 363 (2012).

${ }^{31} \mathrm{~K}$. Vels Hansen, T. Jacobsen, K. Thydén, Y. Wu, and M. Mogensen "In situ surface reduction of a NiO-YSZ-alumina composite using scanning probe microscopy" (unpublished).

${ }^{32}$ A. F. Benton and P. H. Emmett, J. Am. Chem. Soc. 46, 2728 (1924).

${ }^{33}$ J. T. Richardson, R. Scates, and M. V. Twigg, Appl. Catal., A 246, 137 (2003).

${ }^{34}$ J. R. Macdonald and W. R. Kenan, Impedance Spectroscopy: Emphasizing Solid Materials and Systems (John Wiley and Sons, Inc., 1987).

${ }^{35} \mathrm{Y}$. Wu, K. V. Hansen, K. Norrman, T. Jacobsen, and M. B. Mogensen, "Oxygen Electrode Kinetics and Surface Composition of Dense $\left(\mathrm{La}_{0.75} \mathrm{Sr}_{0.25}\right)_{0.95} \mathrm{MnO}_{3}$ on YSZ," ECS Trans. (submitted).

${ }^{36}$ K. Katsiev, B. Yildiz, K. Balasubramaniam, and P. A. Salvador, Appl. Phys. Lett. 95, 092106 (2009). 